\title{
O PAPEL DO MUNICÍPIO NA FORMAÇÃO CONTINUADA DE PROFESSORES DO ENSINO FUNDAMENTAL I
}

\author{
Adrinelly Lemes Nogueira ${ }^{1}$, Lúcia Helena Medeiros ${ }^{2}$ \\ ${ }^{1}$ Doutoranda do Programa de Pós-Graduação em Educação na Faculdade de Educação da Universidade Federal de \\ Uberlândia - UFU, MG. Professora efetiva da Rede Municipal de Educação de Uberaba, MG. E-mail: \\ adrinelly@hotmail.com \\ ${ }^{2}$ Doutora em Educação pela Universidade Estadual de Campinas - UNICAMP, Docente da Universidade Federal de \\ Uberlândia - UFU, MG.
}

\section{RESUMO}

Este artigo se propõe a discutir o papel do município na formação continuada de professores em serviço sob o viés das professoras que atuam em escolas públicas do Triângulo Mineiro. Para aprofundar os estudos sobre a temática nos valemos de autores como Shiroma, Libâneo, Freire, entre outros. Do ponto de vista teórico- metodológico baseamo-nos em Minayo ao afirmar que, fazendo uma reflexão acerca do diálogo entre hermenêutica (compreensão) e dialética (crítica), são trazidos os princípios para operacionalização do método de interpretação de sentidos. Foi realizada uma pesquisa de campo em seis escolas por meio de entrevista semiestruturada com 30 professoras. De forma geral, com base nas análises das muitas vozes ouvidas, entendemos que inúmeras propostas de formação continuada vêm sendo implementadas no decorrer dos anos no referido município e, anunciadas como erradicadoras das dificuldades dos professores, como solução dos seus problemas, mas que ficam no discurso inócuo. Observamos que o papel do município em promover a formação continuada de professores está submetido às políticas públicas nacionais e que não há uma dada continuidade, sobretudo, está à mercê de interesses de âmbito maior, econômicos e políticos em detrimento das necessidades efetivas escola. Desse modo, uma proposta de uma formação realmente continuada só será legítima e significativa quando enriquecer profissionalmente os professores; desse modo, será um processo construído no cotidiano escolar, dentro da própria profissão.

Palavras-chave: Formação de professores. Formação Continuada de Professores. Papel do Município

\section{THE ROLE OF THE CITY IN THE CONTINUED TEACHERS FORMATION IN THE FUNDAMENTAL TEACHING I}

\begin{abstract}
ABSCTRAT
This article proposes to discuss the role of the municipality in the ongoing formation of teachers in service under the bias of the teachers who work in public schools in the Triângulo Mineiro. In order to deepen the studies on the subject we use authors such as Shiroma, Libâneo, Freire, among others. From the theoretical-methodological point of view, we base ourselves on Minayo when affirming that, by making a reflection on the dialogue between hermeneutics (understanding) and dialectic (critical), the principles for the operationalization of the method of interpretation of meanings are brought. A field survey was carried out in six schools through a semistructured interview with 30 teachers. In general, based on the analysis of the many voices heard, we understand that innumerable proposals for continuing education have been implemented over the years in the said municipality and, announced as eradicators of teachers' difficulties, as a solution to their problems, speech innocuous. We observe that the role of the municipality in promoting the continuing education of teachers is subject to national public policies and that there is no continuity, above all, it is at the mercy of larger interests, economic and political at the expense of effective school needs. In this way, a proposal for a truly continuing education will only be legitimate and meaningful when professionally enriching teachers; in this way, it will be a process built in the school routine, within the profession itself.
\end{abstract}

Keywords: Teacher training. Continuing Teacher Training. Role of the Municipality 


\section{INTRODUÇÃO}

Existe intrínseca relação entre as políticas públicas educacionais perfiladas em âmbito nacional, estadual e regional no Brasil, com o projeto histórico capitalista atual, ou seja, com os princípios excludentes do neoliberalismo que se materializam em todos os âmbitos da sociedade e tem influenciado diretamente a formação continuada dos profissionais da educação, em específico, daqueles que atuam no Ensino Fundamental da Educação Básica.

Concorda-se com Libâneo (2012, p.15-16) ao afirmar que, a partir da Declaração de Jomtien (1990), os vinte anos de políticas educacionais no Brasil "selaram o destino da escola pública brasileira e seu declínio", e hoje a escola brasileira é dualista. De um lado, está a "escola assentada no conhecimento, na aprendizagem e nas tecnologias, voltada aos filhos dos ricos, e, em outro, a escola do acolhimento social, da integração social, voltada aos pobres e dedicada, primordialmente, a missões sociais de assistência e apoio às crianças".

Nesse contexto, a ideologia neoliberal tem reflexo direto sobre a formação continuada de professores. A eles é delegada a função de afirmar o dualismo da escola, especialmente, a partir da redução do papel do Estado, da divisão ou entrega de suas funções à iniciativa privada. As políticas públicas resultantes desse dualismo interferem na escolha, no oferecimento e na participação de professores nessas formações. Pois, para os neoliberais, "[...] privatizar, liberalizar, desregular, flexibilizar os mercados de trabalho, mas fazê-lo de forma radical, já que para o neoliberal o Estado deve limitar-se a garantir a propriedade e os contratos, devendo, portanto, desvencilhar-se de todas as suas funções de intervenção no plano econômico e social" (PEREIRA, 1998, p.57).

Nesse sentido, percebe-se na formação de professores, prioridades postergadas, programas aligeirados e descontínuos e priorização de interesses de determinados grupos em detrimento dos interesses do coletivo, são marcas desse processo. Como pensar em uma formação continuada de professores do Ensino Fundamental I de qualidade, se os programas de formação são descontínuos, desconexos da real necessidade dos professores e estes sequer são ouvidos em seus anseios e dificuldades?

Observa-se uma pseudoautonomia do professor em relação à sua formação, e segundo Oliveira (2007), as reformas educacionais que na última década foram implantadas na maioria dos países latinoamericanos foram marcadas pela descentralização administrativa, financeira e pedagógica, atribuindo maior autonomia aos estabelecimentos escolares (OLIVEIRA, 2007, p.366).

Uma autonomia falsa, pois as cobranças impedem que os professores tomem espaços de formação como momentos propícios à discussão de suas dificuldades e possibilidades.

Como destaca Shiroma, Moraes e Evangelista (2011), o professor é o agente da mudança, o responsável pela realização do ideário do séc. XXI; é competente e devoto, autoridade, paciente e humilde. Uma vez treinado, segundo as autoras, os professores poderão levar as crianças à entrada precoce na sociedade da informação, evitar que os adolescentes fiquem desempregados, ou desabem em sentimento de exclusão e ausência de futuro. Possuindo, além de competências pedagógicas, formação para a pesquisa, sendo flexíveis, com um novo estatuto social e com "condições de trabalho adequadas, tais como motivação, remuneração equivalente à formação, incentivos aos que trabalham em lugares afastados" (SHIROMA; MORAES; EVANGELISTA, 2011, p.58-59).

Segundo Shiroma, Moraes e Evangelista (2011), os professores se envolvem nas reformas do ensino e confiam nas vantagens em aderir a elas, creem nas recompensas que poderão obter, caso o resultado de seus alunos seja favorável. Caso consigam melhores resultados em avaliações externas e internas, receberão bônus, prêmios, o que na realidade, é menos salário de verdade, pois eles precisam responder à monitorização e avaliação do Estado. Essa ideia corrobora à Barroso (2005) ao afirmar que o Estado passa a ser regulador e avaliador, para saber se os resultados desejados foram alcançados ou não; caso a resposta seja negativa, a responsabilidade é cobrada apenas do professor e nunca dos acordos, das diretrizes engessadas pela política global e que por via de regra, deságuam nos sistemas de ensino do Brasil. 
Superar a lógica desumanizadora do capital, que tem no individualismo, no lucro e na competição seus fundamentos, como destaca Mészaros (2002), é um grande desafio. Essa tem sido a lógica de qualidade propagada, outras vezes efetivada em nossas escolas: o professor só é competente caso atinja altos níveis de notas em avaliações internas e externas; é a mensuração de qualidade por meio de conceito quantificável. Além disso, a formação continuada de professores, especialmente, em serviço, passa a ser o meio e o fim para obtenção de porcentagens mínimas de aumento salarial. Nos ancoramos em Mészaros (2002), ao discutir que a educação, poderia ser uma alavanca essencial para uma mudança mais humana, porém tornou-se instrumento de perpetuação, afirmação, reprodução de um sistema desumanizador, sobretudo por ser essa a sociedade mais desigual de toda a história. Nela tudo se vende, tudo se compra, tudo tem preço, é a sociedade de consumidores competentes e exigentes. Se, na escola pobre, vende-se um determinado tipo de produto, aquele que leva o aluno ao trabalho, ao contrário, na escola de elite, o produto vendido direciona o aluno aos mais altos cargos, aos cursos mais concorridos, às melhores profissões.

A chamada por uma educação pública de qualidade a todos continua sendo negada pelo poder público, pois, mesmo que muitas ações tenham sido feitas, o princípio que as norteiam é o de resultados e quantidade, e não de qualidade e continuidade. Nossa hipótese é que a proposta de formação continuada, até agora implementada, apenas cumpre um protocolo, explicita e publiciza o feito em nome da qualidade, e, nesse sentido, ela é considerada, em nossa análise, apenas tarefismo.

$\mathrm{E}$, é exatamente essa questão que justifica considerar as identidades e as vozes negadas dos professores, pois ecoam delas, possivelmente, as possibilidades para melhoria na formulação de novos formatos de futuros programas e ações para formação de professores. Partindo desses pressupostos, a questão fulcral a se refletir é como professoras que atuam em escolas públicas em um município do Triângulo Mineiro veem o papel do munícipio que residem na efetivação da formação continuada.

\section{METODOLOGIA}

O esboço dos procedimentos de qualquer pesquisa e a análise de dados depende da opção teórico-metodológica escolhida pelo pesquisador e, nesse sentido, o alicerce tomado é um constante movimento de ir e vir, uma relação com o macro/micro e o objeto de estudo. Pois,

na ciência se demanda a decomposição do todo a fim de apontar o que é específico da coisa, pois, se na investigação cairmos na tentação de querer, de antemão, dizer o que é secundário ou essencial colocamos em risco a própria legitimidade da investigação (RICHTER, 2012, p.238).

Pretende-se, nestas linhas, elaborar a síntese dessas relações, confluindo com o posicionamento teórico de Minayo (2010) ao afirmar que, fazendo uma reflexão acerca do diálogo entre hermenêutica (compreensão) e dialética (crítica), são trazidos os princípios para operacionalização do método de interpretação de sentidos,

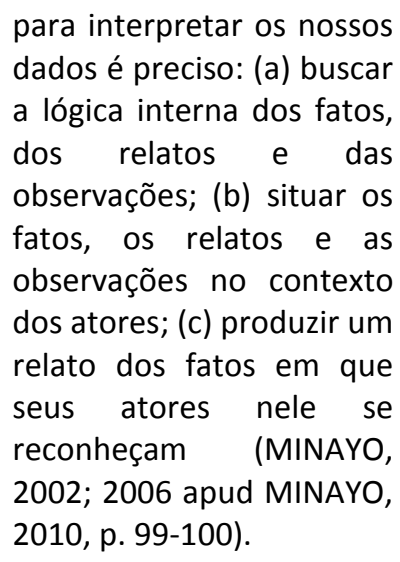

Foi realizada uma pesquisa de campo de cunho qualitativo, na rede municipal/estadual em um município do triângulo mineiro, abrangendo todos os professores do Ensino Fundamental I. Ao todo, seis escolas, cinco municipais e uma estadual participaram da pesquisa, onde 30 professoras nomeadas ficticiamente de P1 a P30, responderam a uma entrevista semiestruturada. A escolha pela entrevista foi com base em Szymanski (2010), quando afirma que a entrevista também se torna um momento de organização de ideias e de construção de um discurso para um interlocutor, momento de construção de um novo conhecimento que se dá na interação. Tal situação foi única, no qual se engendrou um material rico sobre "biografias, experiências, opiniões, valores, aspirações, 
atitudes e sentimentos das pessoas" (MAY, 2004, p.45).

As entrevistas foram degravadas e, posteriormente, iniciaram-se as análises ponderadas à luz da fundamentação teórica, baseadas em categorias,

a) decompor o material a ser analisado em partes (o que é parte vai depender da unidade de registro e da unidade de contexto que escolhemos); b) distribuir as partes em categorias; c) fazer uma descrição do resultado da categorização (expondo os achados encontrados na análise; d) fazer inferências dos resultados (lançando-se mão de premissas aceitas pelos pesquisadores);

interpretar os resultados obtidos com auxílio de fundamentação teórica adotada. Observamos que nem toda análise de conteúdos segue essa trajetória. O caminho a ser seguido pelo pesquisador vai depender dos propósitos da pesquisa, do objeto de estudo, da natureza do material disponível e da perspectiva teórica por ele adotada (MINAYO, 2012, p.88).

Uma das categorias elencadas foi: o papel das Universidades e órgãos federativos na efetivação da formação continuada e, dentro dessa categoria, foram discutidas subcategorias, temáticas de extrema relevância. Nesse texto, fizemos um recorte e apresentamos as questões que condizem com o papel do município, frente ao oferecimento de formação continuada.

\section{RESULTADOS E DISCUSSÃO}

O principal teor desta análise é que a União e todos os entes federativos são responsáveis, em regime de colaboração, por promover a qualidade da educação brasileira, logo, da formação continuada de professores. Nesse sentido, vale ressaltar o art. 8 da LDB: “A União, os Estados, o Distrito Federal e os Municípios organizarão, em regime de colaboração, os respectivos sistemas de ensino" (BRASIL, 1996); o art. 211, da CF de 1988, também diz "A União, os Estados, o Distrito Federal e os Municípios organizarão em regime de colaboração seus sistemas de ensino" (BRASIL, 1988).

Cabe mencionar que, em contraponto, a Emenda Constitucional №95 de 2016 contradiz esse regime de colaboração entre os entes federados, pois estamos falando também de financiamento (nesse caso, quem paga a formação); diante da estagnação dos investimentos para os direitos sociais, a educação e a formação continuada de professores, não evoluirá, o que coloca em risco a valorização dos professores. Nesse contexto, o Estado tem deixado "de ser produtor de bens e serviços para se transformar, sobretudo em regulador do processo de mercado" (AFONSO, 2001, p.25).

Com base em tal legalidade, dirigimos às professoras alguns questionamentos a respeito do papel da União, Estados e Município e da Universidade frente à efetivação da formação continuada. Os sistemas de ensino (federal, estadual e municipal) são responsáveis pela oferta de uma formação continuada de qualidade e sinalizam metas a serem efetivadas pelos entes federados; mas, em função da não regulamentação do regime de colaboração, elas não são concretizadas, como uma destaca uma professora "é preciso que as políticas Públicas de educação funcionem [...] não está só nas nossas mãos, o buraco é bem mais embaixo [...]" (P16). Se a professora relata que não depende apenas do professor a efetivação de políticas públicas de educação, entendemos que o governo municipal, estadual e federal, tem seu papel; prioridade que tem sido postergada, como Freitas (2007) discorre:

a impossibilidade de desenvolvimento de uma formação de caráter emancipador, no interior de um sistema profundamente desigual e excludente, nos marcos do capitalismo, nos permite entender e atuar no campo das contradições e evita que possamos cair na armadilha das soluções fáceis, ágeis e de "menor custo", que caracterizam, via de regra, as iniciativas no âmbito da educação e 
particularmente da formação (FREITAS, 2007, p. 1220).

Inicialmente, assumimos a escola (promovida pelo seu sistema de ensino municipal e estadual) que dentre as várias possibilidades do cotidiano escolar em sua amplitude é apontada como uma das instâncias privilegiadas para a formação do educador em serviço. As inúmeras iniciativas de formação continuada, voltadas para dentro da escola, podem indicar a construção de formações que ultrapassem a mera "comunicação de ideias".

Dada a importância dessa ambiência para a formação, as professoras foram indagadas se a instituição em que atuam proporciona formação continuada e quais ações são realizadas. Uma professora explicou que a escola tem oferecido parcialmente formação continuada: "[...] curso em parceria com a SEE ${ }^{1}$, bem como cursos online [...]" (P4). Porém, 36,6\% das professoras disseram que a instituição em que atuam não a tem proporcionado: "Não, desde quando eu entrei aqui não" (P13); "não pela própria escola, eu não tenho não, o que tem é assim o munícipio que oferece [...]" (P8); "A escola, a rede municipal em si não [...] sempre que existe algum curso na SRE [...] a secretaria de educação do município, proporciona para a gente participar cria brechas, abre vagas, dá condição [...]" (P25).

Quando as professoras destacam que a escola em que atuam não proporciona formação continuada, é preciso entender o porquê desse não oferecimento, uma vez ser ela o espaço ideal para partilhar e construir conhecimentos sobre a prática pedagógica, em um contexto de trabalho coletivo. $\mathrm{Na}$ partilha com os colegas e outros atores da escola, suas identidades vão se construindo, e essa é a ideia principal da formação pois sabemos que o ensino não pode modificar-se sem a participação plena e completa dos docentes.

Boa parte das professoras, destacam em suas falas, que o módulo ${ }^{2}$ é formação continuada. Passamos, então, a pensar o módulo

\footnotetext{
${ }^{1}$ Secretaria Estadual de Educação

${ }^{2}$ De acordo com a Lei Estadual 20.592/12, a carga horária do professor é organizada da seguinte forma: 16 horas semanais destinadas à docência (módulo 1) e 8 horas semanais destinadas à atividades extraclasse (módulo 2 ): sendo 4 horas semanais em local de livre escolha do professor e 4 horas semanais na própria escola ou em local definido pela direção; até duas horas semanais dedicadas a reuniões, totalizando 24 horas semanais, que é a carga horária do Professor de Educação Básica determinada pela Lei Estadual 15.293/04.
}

como uma temática relevante dada a ênfase que as entrevistadas lhe atribuem: “[...] módulos, considero como um tipo de formação continuada" (P9); "[...] o módulo porque a gente vê muita coisa assim referente às matérias que vai aplicar" (P21); "[...] temos módulo uma vez por semana [...]" (P29) (sic). Entretanto, para duas professoras ele é apenas administrativo: "[...] módulos eles não são nada aproveitáveis falar a verdade, porque módulo hoje é muito administrativo, [...]" (P25); "O módulo não considero, é mais para a gente corrigir provas, elaborar aula" (P17).

O módulo é um encontro entre os professores que ocorre toda semana, com carga horária de duas horas. Muitos professores afirmam que é apenas um momento de conversa, de vender mercadorias, perda de tempo ou para preenchimento de papeladas. Infelizmente, esse tempo se desligou de sua tarefa educativa e se reduziu a "cafezinho", "bate papo" e "reuniões esporádicas sobre comemorações". Sabemos que formação continuada em serviço é diferente de reciclagem, práticas pontuais e tarefismo; é o desenvolvimento profissional e permanente, por isso, esse momento deve ser repensado, diante da opinião das professoras, para se tornar um momento que as auxilie em sua docência.

Um momento da formação que poderia ser oportuno para a troca de ideias, experiências e busca de alternativas para solucionar as dificuldades, é esvaziado, sucumbindo às ingerências, por isso, é importante pensar sobre esse espaço com planos e projetos que possibilitem a reafirmação desse momento enquanto espaço de formação. Porque não discutir um texto interessante, organizar palestras, atividades práticas e minicursos nesse tempo que tem sido delegado ao ócio ou até mesmo para repasses de projetos de última hora, pensados de cima para baixo.

Além do módulo, o Pacto Nacional pela Alfabetização na Idade Certa (PNAIC) é citado: "[...] um curso muito bom, o Pacto aquela formação do governo [...] funcionou muito bem, eu gostei" (P23). Maioria das professoras declara que a escola oferece formação continuada em serviço, existem cursos, palestras, oficinas: “[...] palestras com a supervisora, às vezes vem os palestrantes também, que o munícipio traz, sempre quando a gente precisa, ele traz, tem horário de módulo" (P6); "a gente faz bastante 
curso pela SRE [...]" (P2); “[...] MAGISTRA ${ }^{3}$, o MINAS SAÚDE", tem online [...]" (P3); "Sim, O RENAFOR $^{5}$ que eu fiz" (P11). A MAGISTRA e RENAFOR são programas de grande envergadura, na visão das professoras entrevistadas. Assim, pesquisas que fazem avaliação e acompanhamento da forma como a formação é proposta, são fundamentais, sobretudo para que a Universidade possa consolidar mecanismos que tenham relação com a realidade vivenciada pelas professoras participantes.

Ainda discutindo se a instituição em que elas atuam proporciona formação continuada, as falas revelam o papel essencial de uma gestão de qualidade, apontam que é preciso que as formações sejam repassadas ou oferecidas, publicizadas, e cabe à gestão da escola o diálogo e o planejamento para que esses momentos aconteçam para todos: " formação continuada dessas que são sugeridas, pelo governo do Estado, todas que aparece a direção passa [...]" (P20); "quando tem cursos, é sempre falado para a gente fazer [...]" (P12).

Pelas falas anteriores, entendemos que a gestão também é responsável pela formação continuada, por isso deve ser democrática e refletir sobre as necessidades de seus professores e alunos; caso seja hierárquica, será reafirmada, mais uma vez, a ideia de organização de momentos segundo objetivos nada condizentes com as necessidades de seus professores. Entendemos que uma maneira de romper com as formações continuadas em serviço, que seguem uma lógica de imposição, é por meio de uma gestão democrática, pois ela possibilitará a realização de um trabalho participativo, ativo e autônomo na escola, envolvendo todos os seus segmentos.

Segundo uma professora, "a VIVO proporciona um curso pra gente, mas não é todos os professores que adere [...] pra escola rural [...] muito bom, eu faço ele online [...]" (P27). Aqui, aparece a discussão da parceria público-privada, subcategoria aqui discutida, pois é recorrente nas afirmações das professoras. Ao citar a empresa

\footnotetext{
3 Escola de Formação e Desenvolvimento Profissional de Educadores

4 O Canal Minas Saúde foi uma rede estratégica multimídia de $\mathrm{TV}$, rádio e web criada para o desenvolvimento de cursos de capacitação em educação a distância, além de ampla produção conteúdo informativo audiovisual para a promoção da saúde e do Sistema Único de Saúde (SUS). Disponível em: < http://www.saude.mg.gov.br/farmaciadetodos/action/15-canalminas-saude >

${ }^{5}$ Rede Nacional de Formação Continuada

${ }^{6}$ Fundação Telefônica Vivo.
}

de telecomunicações como instituição que proporciona formação continuada, destacamos que é necessário discutir a qualidade desses cursos. Pois, se notamos sinais vitais da gestão compartilhada, aquela que também é um elemento da política pública da gestão escolar, não deixa de ser

contraditória em relação à prática democratizadora. Sua marca principal é a de responsabilizar

a
comunidade pelo fracasso escolar, pelo abandono da escola. Busca, assim, não compartilhar o poder de decisão, mas compartilhar o poder de manutenção. De participação tem somente o elemento radical, acrescentado de prefixo e sufixo "com" e "ada"; a partilha que se destina é aquela que envolve responsabilização sem deliberação, manutenção sem poder de decisão, ou seja, da radicalidade da participação transformadora, a gestão compartilhada não herda nada (LIMA; PRADO; SHIMAMOTO, 2011, p. 89).

Sabemos que o professor, muitas vezes, não está preparado para atender às demandas cotidianas que lhes são exigidas; inúmeros projetos internacionais e programas mineiros têm tratado a re (formação) docente como saída e solução desses embates. Mas, parece-nos, implicitamente, que as professoras mostram a ideia de uma formação em massa e aligeirada oferecida por parcerias público-privadas, o que levaria a um quadro de desprofissionalização docente.

Segundo Shiroma (2011, p.6): "Discursos neoliberais tentam nos convencer de que não faltam professores, faltam 'bons' professores e 'escolas eficazes', de que não faltam recursos para educação, apenas são mal aplicados e mal geridos". Logo, "[...] bons professores são frutos de uma boa gestão mais do que de uma boa formação ou de condições de trabalho e salários adequados". Um discurso estritamente esvaziado: professores precisam, sim, de uma 
boa formação, de salários dignos, de sua valorização docente; o ideal seria "[...] proporcionar mais formação continuada, mas aí não é o problema da escola, é problema do governo [...]" (P16).

Diante disso, quanto ao oferecimento de formação continuada pela escola, entendemos que é preciso investigar se as formações oferecidas por ela são de qualidade ou não, se partem das necessidades dos professores ou são apenas repassadas do Estado ou de outras instituições. É essencial e urgente discutir o trabalho coletivo e a formação dentro da própria escola; questionamos, ainda, as professoras, se o município oferece formação continuada, solicitando e que falassem sobre as ações existentes. Uma professora preferiu não comentar: "não moro aqui, então eu não posso falar" (P1).

Algumas professoras não responderam à questão claramente, outras, por pertencerem à escola estadual não disseram nada sobre 0 município: "Eu fiz o curso da área de surdez pelo estado, fiz o curso de autismo [...] no MAGISTRA [...]" (P2); "[...] mulher queria trazer pra gente, mas houve momentos de conflito [...] tenho um aluno que ele tem problema [...] fui fazer esse curso, porque eu queria uma luz [...] pediu pra gente aceitar que o menino é daquele jeito mesmo, que ele tem direito de estar lá na sala e pronto acabou" (P3) (sic).

As entrevistadas fazem alusão à educação especial e inclusiva, pois é nesse contexto de reformas educacionais, aliadas aos pressupostos neoliberais, que ocorre a disseminação das políticas de inclusão e de educação para todos; a formação continuada tem sido estratégica para amparar professores que atuam diretamente com a educação inclusiva.

Nas falas das professoras, evidenciamos que elas reiteram as ações do Estado, por exemplo, a MAGISTRA, já apresentada; revelam ainda que procuram cursos com base nos problemas da sala de aula, procuram auxílio, mas não o encontram; inferimos que a forma como se organiza a formação que ora se institui, no sistema estadual e municipal de educação, muito se distancia da realidade dos professores e da necessidade que a escola apresenta.

Uma professora salienta: "pra mim não, eu acho que teve pra alguns professores aí, eu acho que tinha que ter o nível superior completo pra poder fazer esse curso, e eu como eu ainda estou formando" (P28) (sic). Retomando as discussões anteriores, em 2013, segundo o MEC/INEP, $72,4 \%$ dos professores tinham formação superior; em 2014, conforme BRASIL (2016), apenas 76,2\% dos professores da Educação Básica tinham ensino superior completo, um quarto deles lecionava mesmo sem ter formação superior. Tal quadro ainda é preocupante e precisa ser melhor investigado.

Outra professora ressalta que é preciso uma melhor estruturação dessas formações existentes: "[...] ser com maior frequência, com uma melhor estruturação, não adianta só a pessoa chegar e blá, blá [...]" (P26) (sic). Sublinham que existe uma palestra no início e no fim do ano no município: "começo de ano, final de ano, ele traz as palestrantes [...]" (P7). Outra professora também relata que o "[...] município oferece lá um seminário ou outro quando vai iniciar o semestre, isso não é formação continuada, você ouvir uma palestra não é formação continuada [...] hoje você baixa uma palestra da Internet [...]" (P25); contudo, em seu entendimento, algumas horas não abarcam a extensão de uma formação continuada, assim, utilizamos a subcategoria tarefismo para ressaltar a falta de continuidade das ações.

Entendemos que uma palestra de poucas horas não pode ser considerada formação continuada; é apenas "sejam bem-vindos" e, muitas vezes, com assuntos nada interessantes e/ou significativos. O barateamento de recursos e o aligeiramento podem levar a ações e atividades insatisfatórias; ao tarefismo, quando a formação continuada chega pronta, ela conflui para a desvalorização do professor e dos seus saberes experienciais, pois não parte de suas necessidades e anseios. É de extrema importância que o munícipio e o Estado revejam sua proposta de oferta da formação continuada, e, especialmente se debrucem sobre as possibilidades para garanti-la aos docentes.

Algumas professoras entrevistadas afirmam que o município oferece formação continuada. Porém, nos chama a atenção a afirmação de uma professora: o munícipio não oferece, mas dá condições para participar: "Oferecer não, mas ele te dá condição de participar [...]" (P25). Conforme o Estatuto do Magistério e Plano de Cargos e Carreira dos Servidores do Magistério Público Municipal do município (LEI no 2.173/2008), os professores devem "participar de cursos, atividades e programas de capacitação profissional, quando convocado ou convidado; promover e participar 
de atividades complementares ao processo da sua formação profissional".

Nesse documento, em relação às gratificações por qualificação, por exemplo, é "deferida à gratificação de incentivo ao aperfeiçoamento funcional, no valor de $10 \%$ (dez por cento) "; quanto à pós-graduação, para quem apresentar um diploma, $12 \%$; para dois diplomas de pós-graduação, o valor é 15\%; mestrado, 18\%; e doutorado, $20 \%$. Porcentagens "incidentes sobre o vencimento base previsto na matriz de vencimentos para o cargo que ocupa" (LEI no 2.173/2008).

Percebemos, assim, que, dentre as atribuições dos professores, está a formação continuada e que o município tem um plano de gratificação por qualificação pouco estimulante, a nosso ver, pois o aumento salarial é mínimo. É necessário refletir se os professores têm conhecimento sobre essas questões e se é interessante conscientizá-los a respeito disso. Segundo o "art. 46 - A gratificação de que tratam os artigos anteriores não é cumulativa e será deferida uma única vez para cada grau de titulação, sendo que a gratificação de maior titulação excluirá a de menor" (LEI no 2.173/2008). É necessário o conhecimento por parte das professoras dessa legislação e de seus direitos, sobretudo que elas não busquem uma qualificação, por exemplo, pensando apenas em gratificação, pois são profissionais em formação e devem buscar constantemente atualizar seus conhecimentos e superar dificuldades.

Nessa análise trabalhamos com a perspectiva de ser inconcluso com base no pensamento de Freire (1996): ensinar exige também "consciência do inacabamento"; para ele, esse é o ponto do qual se deve partir:

o do inacabamento de ser humano. Na verdade, o inacabamento do ser ou sua inconclusão é próprio da experiência vital. Onde há vida, há inacabamento. Mas só entre mulheres e homens o inacabamento se tornou consciente (FREIRE, 1996, p.29).

Nesse sentido, o professor, enquanto ser em construção, considerando estar condicionado a um sistema educacional que, por sua vez, é subalterno aos organismos multilaterais, entende-se que o exercício de superação é muito grande, mas deve lembrar que a "formação continuada é um processo histórico e inacabado, vinculado às questões da profissão docente e da educação como prática social" (PEREIRA, 2016, p.11).

Continuando o debate sobre o papel do município, indagamos às professoras se ele deve oferecer maiores oportunidades de encontro entre os professores: $76,66 \%$ afirmam que sim, devem ocorrer maiores oportunidades de encontro, pois o município é o mediador de algumas ações em âmbito nacional: "Deve, por mais que eu faço, ainda acho que está pouco" (P2); "Com certeza, precisa e muito organizar seminários, encontros, trocas de experiência" (P20); "Pra melhoria da prática eu acho que seria até bom pro município, se isso ocorresse" (P10); "Eu acho que sim, eu acho que a gente juntar, a gente troca experiências, dúvidas [...]" (P12) (sic). $O$ restante das professoras relata que depende da qualidade e se serão liberadas para participação.

Nesse sentido, para estudos futuros, cabe aprofundar a discussão sobre a avaliação do município em relação ao que ele oferece aos professores e acerca do que os documentos do município indicam. Já as falas das entrevistadas apontam algumas atividades, duas vezes ao ano, o que ainda é pouco tendo em vista as suas necessidades, o que denota que há pouco investimento nesse sentido. Então, como podemos dizer, diante dessas falas, que as políticas municipais colaboram para o desenvolvimento de qualidade dos professores e para a melhoria da educação em geral?

O discurso perfeito, principalmente, veiculado pelas mídias e pelos documentos oficiais, indica uma educação sem problemas, com boa estrutura, notória formação e resultados satisfatórios. Os órgãos públicos divulgam a educação brasileira de qualidade, mas não cumprem adequadamente o que se é de seu dever. As professoras problematizam e comentam alguns aspectos preocupantes, como a dobra de turno para complementar o seu salário: "[...] muita gente que não tem tempo entendeu, tem dois cargos [...]" (P12); assim, mesmo que tenha oferta, pelo município, elas não participam. Nesse sentido, o problema é grave, uma vez que garantir o acesso do professor aos cursos de formação continuada não basta. O município e o Estado precisam garantir a permanência deles nos cursos, com a flexibilização de horários, com cobertura e substituto para aquele que participa, enfim, faz- 
se necessário um planejamento para a efetivação da formação continuada: "[...] um curso para todos [...] com continuação" (P14).

O município deve ofertar maiores oportunidades de encontros entre os professores. Nesse âmbito, outro assunto abordado é a relevância da formação continuada para professores iniciantes, diante dos desafios que enfrentam na prática e para os quais não estão preparados: "[...] vindo muito despreparado, porque você sai de uma faculdade sem prática nenhuma então é através desses cursos que você vai aprendendo e o dia a dia [...]" (P17). Sabemos que muitos professores se sentem abandonados no ambiente escolar e que não recebem o apoio necessário. Assim, o momento de formação continuada deve ser dinâmico para a melhoria permanente do professor e não para a transmissão de conteúdos desconexos com a realidade, por vezes, apenas tarefismo. Infelizmente, os programas de formação continuada em pauta neste texto, consideram o professor da fase inicial e aquele que já conquistou uma ampla experiência como iguais, o que não explicita a realidade, afinal, dificuldades e anseios podem diferentes.

Ainda relatando a opinião das professoras se $o$ munícipio deve oferecer maiores oportunidades de encontro: "encontros sim [...] acredito que o município não tem condição de estar oferecendo cursos de formação continuada [...] a escolha do livro didático [...] tinha que ter um tempo sentar, pegar $\mathrm{O} \mathrm{CBC}^{7}$, a matriz curricular nacional, verificar o que tem dentro da matriz [...] infelizmente eu tenho que ensinar hoje, o que está me sendo cobrado, tanto na matriz curricular quanto no CBC" (P25).

A esse respeito, o estado de Minas, via SEE/MG, publicou a resolução $\mathrm{n}$-666, de 07 de Abril de 2005, estabelecendo os CBCs a serem obrigatoriamente ensinados pelas unidades de ensino estaduais que oferecessem as séries finais do Ensino Fundamental e Médio (MINAS GERAIS, 2005). Um ponto de destaque, na fala da P25, é em relação à formação continuada para análise das políticas, como o CBC, para que os professores possam trabalhar de acordo com esses conteúdos; sabemos que a padronização de conteúdos é um meio de silenciar os professores porque de certo modo, impõe um determinando currículo.

\footnotetext{
${ }^{7}$ Conteúdos Básicos Comuns (CBC), publicado em 2005 pela Resolução 666.
}

E em relação à falta de condição do munícipio para criar espaços formativos para os professores em formação continuada em serviço, apontada também pela P25, entendemos que, apesar da existência de uma política, de programas e planos de formação continuada de professores e dos respaldos legais, o município enfrenta dificuldades na execução das ações. Ressaltamos que a construção de um movimento nacional, em prol da qualidade da formação continuada e da educação, exige alguns aspectos fundamentais, entre eles:

associada à necessidade de uma sólida política de formação inicial e continuada, bem como à estruturação de planos de carreira compatíveis aos profissionais da educação, destaca-se a importância de políticas que estimulem fatores como motivação, satisfação com o trabalho e maior identificação com a escola como local de trabalho, como elementos fundamentais para a produção de uma escola de qualidade (DOURADO; OLIVEIRA, 2009, p. 212).

Entendemos que é necessária a continuidade dos programas indo além do tarefismo, no sentido de garantir acesso e permanência, pois muitas atividades são fatiadas ou resumidas e não abarcam a amplitude da docência. Para além do que já apontamos, é necessário consultar os professores, o que querem e porque querem que sejam oferecidas maiores oportunidades de encontros entre os professores: "[...] depende da qualidade do que vão oferecer, se for uma coisa muito repetitiva, os ouvidos já não aguentam mais [...] tem que ser novidade [...]" (P23).

Ao afirmarem que é necessário sair da mesmice, evidenciamos um indicativo de que os programas de formação continuada não estão atentos às suas reais necessidades. Não se trata de satisfazer tais necessidades, mas de cumprir algumas metas já propostas dentro de uma lógica produtivista, já que os sistemas de ensino têm o papel de oferecer formação continuada, conforme a meta 16 do Plano Nacional de Educação (2014), (BRASIL, 2014). Portanto, a realidade delineada até o momento é complexa e 
contraditória: uma formação caótica, postergada, um tarefismo. Há ausência de uma política global que tem relação profícua com as realidades regionais e locais, como Freitas (2007, p.1204) declara: "[...] a má qualidade da formação e a ausência de condições adequadas de exercício do trabalho dos educadores se desenvolvem há décadas, em nosso país".

\section{CONCLUSÃO}

Compreendemos que as metas propostas para melhoria da formação do professor, estão sendo postergadas há tempos. Uma avalanche de medidas baseadas em princípios que em nada condizem com a realidade brasileira tem sido a base de sustentação das propostas formativas do sistema de ensino brasileiro; o compósito das proposições tem reafirmado as desigualdades sociais, não resolvendo os problemas do ensino brasileiro, já que o interesse dos grupos dominantes não é o da maioria da população brasileira.

De forma geral, com base nas análises das muitas vozes ouvidas, percebemos que a formação continuada, a formação continuada em serviço, ainda tem ocorrido enquanto tarefismo; entendemos que inúmeras propostas de formação continuada vêm sendo implementadas no decorrer dos anos, anunciadas como erradicadoras das dificuldades dos professores, como solução dos seus problemas, mas que ficam no discurso inócuo.

Notamos empiricamente que o papel do município em promover a formação continuada de professores está submetido às políticas públicas nacionais e que não há uma dada continuidade, sobretudo, está à mercê de interesses de âmbito maior, econômicos e políticos, do que aos pedagógicos e educacionais. A formação continuada não condiz à necessidade real dos professores, e tampouco resultam na melhoria da prática docente, sobretudo, não é contínua. Por meio de um discurso de descentralização, de maior autonomia e de delegação a cada ente federado de seu papel, muitas vezes, a realidade das escolas não vem à tona, não se parte delas, de dentro delas, para fazer a formação.

A proposta de uma formação realmente continuada só será legítima e significativa quando enriquecer profissionalmente os professores; desse modo, será um processo construído no cotidiano escolar, com a participação de professores atuantes advindos de universidades para mediarem os encontros e estudos, considerando a importância dessas instituições como fonte de pesquisas, troca de informações e saberes.

\section{REFERÊNCIAS}

AFONSO, Almerindo Janela. Reforma do Estado e Políticas Educacionais: entre a crise do EstadoNação e a emergência da regulação supranacional. Educação \& Sociedade, v.22, n.75, ago./2001. Disponível em: $<$ http://www.scielo.br/pdf/es/v22n75/22n75a03. pdf $>$. Acesso em: 20 dez. 2016.

BARROSO, João. O Estado, a Educação e a Regulação das Políticas Públicas. Educ. Soc., Campinas, vol. 26, n. 92, p. 725-751, Especial Out. 2005. Disponível em: <http://www.scielo.br/pdf/es/v26n92/v26n92a0 2.pdf>. Acesso em: 29 jun. 2016.

BRASIL, Constituição (1988). Constituição da República Federativa do Brasil. Brasília, DF: Senado Federal: Centro Gráfico, 1988. Disponível em:

<http://www.planalto.gov.br/ccivil_03/constituic ao/constituicao.htm> Acesso em: 20 dez. 2016.

BRASIL. Lei no 13.005, de 25 de junho de 2014. Aprova o Plano Nacional de Educação (PNE) e dá outras providências. Diário Oficial da União [da] República Federativa do Brasil, Brasília, 2014. Disponível em: <pne.mec.gov.br/>. Acesso em: 01 set. 2018.

BRASIL. Ministério da Educação. Observatório do PNE. Brasília, $2016 . \quad$ Disponível em: <http://www.observatoriodopne.org.br/metaspne>. Acesso em: 12 ago. 2016

BRASIL. Emenda Constitucional №95 de 2016. Altera o Ato das Disposições Constitucionais Transitórias, para instituir o Novo Regime Fiscal, e dá outras providências. Disponível em: <http://www2.camara.leg.br/legin/fed/emecon/ 2016/emendaconstitucional-95-15-dezembro2016-784029-publicacaooriginal-151558pl.html>. Acesso em: 01 set. 2018.

DOURADO, Luiz Fernandes; OLIVEIRA, João Ferreira. A qualidade da educação: perspectivas e desafios. Cad. Cedes, Campinas vol. 29, n. 78, p. 201-215, maio/ago. 2009. Disponível em: 
<http://www.scielo.br/pdf/ccedes/v29n78/v29n7 8a04.pdf>. Acesso em: 18 set. 2016.

FREITAS, Helena Costa Lopes de. A (nova) política de formação de professores: a prioridade postergada. Educ. Soc., Campinas, vol. 28, n. 100 Especial, p. 1203-1230, out. 2007. Disponível em: <http://www.scielo.br/pdf/es/v28n100/a262810 0.pdf>. Acesso em: 01 fev. 2016.

FREIRE, Paulo. Pedagogia da Autonomia: Saberes necessários à prática educativa. São Paulo/ SP: Paz e Terra, 1996 (Coleção Leitura).

LIBÂNEO, José Carlos. O dualismo perverso da escola pública brasileira: escola do conhecimento para os ricos, escola do acolhimento social para os pobres. Educação e Pesquisa, São Paulo, v. 38, n. 1, p. 13-28, 2012. Disponível em: <http://www.scielo.br/pdf/ep/v38n1/aop323.pdf >. Acesso em:11 ago. 2016.

LIMA, Antonio Bosco de.; PRADO, Jeovandir Campos do; SHIMAMOTO, Simone Vieira de Melo. Gestão democrática, gestão gerencial e gestão compartilhada: novos nomes velhos rumos. In:SIMPÓSIO BRASILEIRO, 25., CONGRESSO IBERO-AMERICANO DE POLÍTICA E ADMINISTRAÇÃO DA EDUCAÇÃO - JUBILEU DE OURO DA ANPAE (1961-2011),2., 2011, São Paulo. Anais...São Paulo: ANPAE, 2011. Disponível em:

<http://anpae.org.br/simposio2011/cdrom2011/ PDFs/trabalhosCompletos/comunicacoesRelatos/ 0069.pdf >. Acesso em: 25 out. 2016.

MAY, Tim. Pesquisa Social: questões, métodos e processos. Porto Alegre: Artmed, 2004.

MÉSZÁROS, Istévan. Educação para além do capital. São Paulo: Boitempo, 2002.

MINAYO, Maria Cecília de Souza. Trabalho de campo: contexto de observação, interação e descoberta. In: DESLANDES, Suely Ferreira. GOMES, Romeu. MINAYO, Maria Cecília de Souza (Org.). Pesquisa social: teoria, método e criatividade. 29. ed. Petrópolis: Vozes, 2010. p. 61-77. Disponível em: $<$ https://mariogaudencio.wordpress.com/2013/0 1/02/maria-cecilia-de-souza-minayo/>. Acesso em: 02 abr. 2016.
MINAYO, Maria Cecília de Souza (org). Pesquisa Social: teoria, método e criatividade. 32. ed. Petrópolis, RJ: Vozes, 2012.

MINTO, Lalo Watanabe. O público e o privado nas reformas do ensino superior brasileiro: do golpe de 1964 aos anos 90. Dissertação (Mestrado em Educação) Faculdade de Educação da Universidade Estadual de Campinas, Campinas, $2005 . \quad$ Disponível em: <http://repositorio.unicamp.br/bitstream/REPOSI P/253611/1/Minto_LaloWatanabe_M.pdf>.

Acesso em: 21 nov. 2016.

OLIVEIRA, Dalila Andrade. Política educacional e a re-estruturação do trabalho docente: reflexões sobre o contexto Latino-Americano. Educ. Soc., Campinas, vol. 28, n. 99, p. 355-375, maio/ago. $2007 . \quad$ Disponível em: <http://www.scielo.br/pdf/es/v28n99/a04v2899. pdf >. Acesso em: 06 out. 2016.

PEREIRA, Luiz Carlos Bresser. A reforma do Estado dos anos 90: lógica e mecanismos de controle. Lua Nova Revista de Cultura e Política, n. 45, 1998 49-95. Disponível em: <http://www.bresserpereira.org.br/papers/1998/ A_reforma_do_Estado_dos_anos_90.pdf $>$.

Acesso em: 10 ago. 2016.

PEREIRA, Viviane Carrijo Volnei. Formação continuada de professores alfabetizadores $e o$ processo de constituição da profissão docente. Anais - V Congresso Ilbero Americano e VIII Congr esso Luso Brasileiro, 2016. Disponível em: < http://anpae.org.br/iberoamericano2016/eixo3 .html>. Acesso em: 20 set. 2016.

RICHTER, Leonice Matilde. Clássico marxista: "dialética do concreto". Resenha. Revista Educação e Políticas em Debate - v. 1, n. 1, jan./jul. 2012. Disponível em: <http://www.seer.ufu.br/index.php/revistaeduca opoliticas/article/viewFile/17383/9538>. Acesso em 06 dez. 2016.

SHIROMA, Eneida Oto. A formação do professorgestor nas políticas de profissionalização. Revista e-curriculum, São Paulo, v.7 n.2, Agosto 2011. Disponível em: <http://revistas.pucsp.br/index.php/curriculum/a rticle/download/6778/4905>. Acesso em: 09 mar. 2016. 
SHIROMA, Eneida Oto; MORAES, Maria Célia Marcondes de.; EVANGELISTA, Olinda. Política Educacional. 4. ed. Rio de Janeiro: Lamparina, 2011.

Recebido para avaliação: 10/09/2018

Revisado em: 24/11/2018

Aceite Final: 01/12/2018 